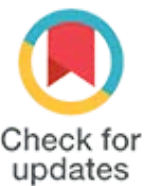

updates

\title{
Assessment of Strain and Strain Rate in Patients with Coronary Artery Disease Before and After Percutaneous Intervention on Left Anterior Descending Coronary Artery
}

\author{
Ali Heidari Sarvestani 1,* (D), Ahmad Separham ${ }^{1}$ (D), Naser \\ Khezerloo $^{1}$ \\ ${ }^{1}$ Department of Cardiology, Tabriz University of Medical Sciences, Tabriz, \\ Iran \\ ${ }^{*}$ Corresponding author: Ali Heidari Sarvestani, Fellowship of Interventional \\ DOI: 10.29252/ijcp-24016 Cardiology, Tabriz University of Medical Sciences, Tabriz, Iran, E-mail: \\ ali.heidari2020@gmail.com
}

\begin{tabular}{l} 
Submitted: 14-01-2019 \\
Accepted: 10-03-2019 \\
\hline Keywords: \\
Coronary Artery Disease \\
Echocardiography \\
S Rate \\
SR Rate \\
\hline (C) 2019. International Journal \\
of Cardiovascular Practice.
\end{tabular}

\section{INTRODUCTION}

Ischemic heart disease is the single most frequent cause of death in American men and women [1]. Echocardiography is the first imaging procedure for diagnosis and evaluation of all cardiovascular disorders. In recent years by development of specified software packages, ultrasonic strain and strain rate imaging (SRI) have been shown to be clinically useful for quantifying cardiac function $[2,3]$. Briefly, strain (S) and strain rate (SR) are deformation and distortion measures. $S$ defines the direct myocardial contractile pattern and explains the percentage of dimensional changes. A negative value shows shortening or contraction and defines lengthening or relaxation. SR however, defines the rate of distortion which is the change in $S$ value within a certain period of time. SR is calculated from the velocity gradients between the two points in the direction of the ultrasound beam with a unit of $1 /$ second $(s-1)$ [4, 5]. As the neighboring tethering effects and the rotational motion of the heart do not affect S/SR, this technique may be more valuable than tissue doppler imaging (TDI) [4-8]. On the other hand, the sensitivity of SR makes it a very effective tool in evaluation of subclinical heart diseases like myocardial involvement in non-cardiac diseases such as amyloidosis, diabetic heart 
disease and in distinction of hypertrophy caused by hypertension and cardiomyopathy [9-15]. Evaluating changes of $S$ parameters in an individual has been shown to be very effective for response to treatment in diseases such as hypertensive heart disease [16], diabetes [17] and Fabry disease [18]. Echocardiographic studies confirmed that with increasing the severity of acute ischemia, a progressive decrease occurs in S/SR levels. Another interesting point is that studies showed similar changes in S/SR indices during percutaneous coronary intervention (PCI) and in some cases these indices decreased suddenly even to $50 \%$ during PCI in the pertinent segments. Over the last three decades, PCI for the treatment of coronary artery disease has developed dramatically [19]. In various studies beneficial effects of PCI in reducing mortality and ischemic symptoms and its role in improvement of fatal and non-fatal cardiac events, have been evaluated. One important aspect of PCI is its improving effect in systolic and diastolic functions based on exact parameters of echocardiography. During early stages of myocardial ischemia and cardiomyopathy S and SR values change and these changes can be used for accurate assessment of cardiac function and left ventricle inter-ventricular mechanical dys-synchrony [1]. Therefore, we planned to assess $\mathrm{S}$ and SR indices in systolic phase in patients with significant stenosis of left anterior descending (LAD) before and after PCI to assess whether S and SR indices change after PCI and if we can use them as predictors of successful PCI.

\section{METHODS}

The study protocol was reviewed, and approved by the Review Board of Tabriz University of Medical Sciences High Research Council. Forty-eight patients (30 females and 18 male), with significant LAD lesion, candidate for non-emergency PCI, were enrolled. Inclusion criteria were having a stenosis $\geq 70 \%$ in $\mathrm{LAD}$, left ventricular ejection fraction $\geq 40 \%$ in echocardiography before PCI and minimum 40 to maximum 75 years of age. All patients with moderate or severe valvular heart disease, a history of previous myocardial infarction or electrocardiographic evidence of infarction, a left bundle brunch block on electrocardiography, wide collateral network in coronary angiography, atrial fibrillation rhythm and unsuccessful PCI defined as remaining stenosis $\geq 40 \%$ or failure to achieve TIMI Flow 3 were excluded from the study. Patients underwent echocardiography a day before and a week after PCI. Echocardiography was performed by a fellowship of echocardiography at rest in the left lateral decubitus position in Apical (four, two, three chamber) and parasternal (long, short axis) views with a Vivid7 digital ultrasound scanner (GE, Milwaukee, Wisconsin, The USA) equipped with a 3.5 $\mathrm{MHz}$ probe. Echocardiographic scope of LAD was defined as anteroseptal, mid septal and apical segments. $S$ and SR indices were assessed separately before and after PCI in all segments at systolic phase.

\section{Statistical Analysis}

Parameters were compared by Paired T test before and after PCI using SPSS 17.0 (Statistical Package for the Social Sciences, Chicago, IL, The USA). For evaluation of the association between quantitative variables and qualitative variables, the Pearson correlation coefficient and Chi-square were used respectively.

\section{RESULTS}

Mean age of patients was $57.4 \pm 10.9$ years (ranging 45 72). From 48 patients (30 female and 18 male) candidate for PCI with significant LAD lesion, about $67 \%$ had hypertension, $46 \%$ diabetes and $31 \%$ were active smoker. The values obtained in each segment before and after PCI compared separately. In each segment, $S$ and SR average values analyzed before and after PCI. As shown in Table 1 , increasing $S$ values was observed in six segments of total nine segments in the territory of $\mathrm{LAD}$, but it was not statistically significant except in two segments of mid-anterior and apicoseptal segments. As shown in Table 2 about the SR values, of total nine segments in LAD territory, there was an increase in eight segments and it was statistically significant in four segments (mid-septal, apico-septal, mid-anterior and basal anteroseptal segments).

$\underline{\text { Table 1. Comparison of Strain (S) Values in Different segments before and after PCI }}$

\begin{tabular}{|c|c|c|c|}
\hline & Post PCI S & Pre PCI S & P value, (CI: 95\%) \\
\hline \multicolumn{4}{|l|}{ Septal } \\
\hline Mid & $-18.69 \pm 6.24$ & $-17.59 \pm 6.22$ & 0.1 \\
\hline Apical & $-21.93 \pm 6.98$ & $-19.75 \pm 5.80$ & 0.001 \\
\hline \multicolumn{4}{|l|}{ Anterior } \\
\hline Basal & $-19.81 \pm 7.89$ & $-18.01 \pm 9.06$ & 0.2 \\
\hline Mid & $-16.79 \pm 7.46$ & $-15.25 \pm 6.90$ & 0.02 \\
\hline Apical & $-7.83 \pm 5.12$ & $-7.97 \pm 5.47$ & 0.8 \\
\hline \multicolumn{4}{|c|}{ Anteroseptal } \\
\hline Basal & $-13.51 \pm 7.70$ & $-12.44 \pm 5.96$ & 0.4 \\
\hline Mid & $-17.97 \pm 4.39$ & $-18.03 \pm 3.51$ & 0.9 \\
\hline \multicolumn{4}{|l|}{ Lateral } \\
\hline Apical & $-10.58 \pm 4.09$ & $-11.04 \pm 7.06$ & 0.5 \\
\hline \multicolumn{4}{|l|}{ Inferior } \\
\hline Apical & $-22.38 \pm 7.21$ & $-23.23 \pm 10.26$ & 0.6 \\
\hline
\end{tabular}

Results are shown as mean \pm standard deviation

CI: Confidence interval; PCI: Primary Coronary Intervention 
Table 2. Comparison of Strain Rate (SR) values in different segments before and after PCI

\begin{tabular}{|c|c|c|c|}
\hline & Pre PCI SR & Post PCI SR & P value, (CI: 95\%) \\
\hline \multicolumn{4}{|l|}{ Septal } \\
\hline Mid & $-1.13 \pm 0.23$ & $-1.35 \pm 0.31$ & 0.0001 \\
\hline Apical & $-1.27 \pm 0.26$ & $-1.51 \pm 0.82$ & 0.05 \\
\hline \multicolumn{4}{|l|}{ Anterior } \\
\hline Basal & $-1.43 \pm 0.64$ & $-1.75 \pm 1.14$ & 0.09 \\
\hline Mid & $-0.95 \pm 0.48$ & $-1.04 \pm 0.49$ & 0.03 \\
\hline Apical & $-0.66 \pm 0.27$ & $-0.59 \pm 0.43$ & 0.3 \\
\hline \multicolumn{4}{|c|}{ Anteroseptal } \\
\hline Basal & $-1.00 \pm 0.42$ & $-1.34 \pm 0.53$ & 0.0001 \\
\hline Mid & $-1.19 \pm 0.30$ & $-1.21 \pm 0.36$ & 0.6 \\
\hline \multicolumn{4}{|l|}{ Lateral } \\
\hline Apical & $-0.757 \pm 0.33$ & $-0.759 \pm 0.32$ & 0.9 \\
\hline \multicolumn{4}{|l|}{ Inferior } \\
\hline Apical & $-1.71 \pm 1.52$ & $-1.72 \pm 0.92$ & 0.9 \\
\hline
\end{tabular}

Results are shown as mean \pm standard deviation,

CI: Confidence interval; PCI: Primary Coronary Intervention

Table 3. Comparison of Strain (S) and Strain Rate SR) values before and after PCI

\begin{tabular}{lccc} 
& Pre PCI & Post PCI & Pvalue (CI: 95\%) \\
\hline Strain (S) & $-143.36 \pm 29.08$ & $-149.54 \pm 25.77$ & 0.1 \\
Strain rate (SR) & $-10.12 \pm 2.34$ & $-11.30 \pm 2.41$ & 0.001 \\
\hline
\end{tabular}

Results are shown as mean \pm standard deviation,

CI: Confidence interval; PCI: Primary Coronary Intervention

In short, $\mathrm{S}$ values showed significant increase after PCI only in two segments and SR values showed significant increase after PCI in four segments. In the analysis of sum of mean parameters, as shown in Table $3, \mathrm{~S}$ values did not increase significantly ( 143.36 to 149.54 ; P value: 0.1 ), but $S R$ values increased significantly (10.12 to 11.30; P value: 0.001 ).

\section{DISCUSSION}

In general, this study showed that remedial effect of PCI on the deformation values was observed in the first week and SR values showed significant increase in this period. Heimdal et al. did the first clinical study on SRI to learn the feasibility to demonstrate the use of SRI for regional dysfunction. Their study was performed on six patients with myocardial infarction [20]. SRI played as a valuable physiological tool for understanding myocardial mechanics. Unlike TDI, the application of SRI in standard clinical practice has not been well investigated. Traditional method of evaluating regional ischemia based on heart wall motion and wall thickness has some restrictions in timing of regional myocardial changes. Using TDI has been eliminated some of these limitations, but measurement errors exist due to motion translation and tethering still. S and SR imaging can substantially overcome these limitations [21].

Echocardiographic studies proved that progressive decrease occurs in S and SR values with increasing the severity of ischemia. These changes occur even before changes in TDI parameters or regional wall motion abnormalities [22].

Only few studies have been performed to assess the effects of PCI on S and SR values, and different results were obtained. Also, changes in S and SR values in ischemic heart disease investigated in many studies. For example in a study by Aksakal and colleagues in 2010, $\mathrm{S} / \mathrm{SR}$ echocardiography was performed before and after PCI in patients with acute anterior myocardial infarction. They found that $S$ and SR values were significantly decreased within the first six hours of acute myocardial infarction. The first echocardiographic recordings were obtained just before PCI and subsequent echocardiographic recordings were obtained one week and one month after the PCI. A significant increase in the apical segments both in the first week and in the first month were observed indicating that these segments benefit more from PCI. These finding may show that $S$ and SR values may be used as markers of post-angioplasty improvement. Low level of deformation indices in the first week and an increase in these indices in the first month reflect that contractile functions recover later despite reperfusion. Briefly, deformation indices were lower in ischemic and necrotic tissues, and for S/SR measurements, a normal ischemic-necrotic distribution was observed. An increase in the first week S/SR values in the normal and ischemic segments compared to the pre-PCI period and its persistence of during the first month regarded as the consequence of a successful PCI. Showing these results in ischemic segments similar to the normal segments is the positive effect of successful PCI in the recovery period [23].

Kukulski et al. in 2002 demonstrated that in unstable angina, $S$ values in normal, hypokinetic, and akinetic segments was decreased by balloon-induced occlusion during elective angioplasty and reached pre-occlusion values via reperfusion. In this study, a significant difference was observed in the dysfunctional segments and between the normal neighboring segments, and also between normal control group segments. Thus, during 
acute ischemic period using $S$ values, dysfunctional segments could be separated from normal segments [24]. In the similar study performed by Tanaka and colleagues the $S$ and SR values were measured before and after PCI in both systolic and diastolic phases and results suggested that PCI had no significant effect on systolic SR in ischemic areas [25]. In another study Liang $\mathrm{H}$ and colleagues found that the SR parameter in patients with coronary obstruction higher than $70 \%$, showed significant decrease compared to the control group [26]. However, there was no significant increase in $S$ values after PCI in these studies. These values were measured only a week after PCI and a significant increase in these parameters may occur over a longer time, as shown in Aksakal's study in which rises in $S$ and SR values continued up to a month after PCI and this increase was particularly noticeable in the apical segment. It seems that using cardiac stress imaging (pharmacologic or exercise) during exercise enhances the sensitivity and specificity of these parameters in predicting response to PCI. In a study by Ojaghi and colleagues, the effect of PCI on S and SR were studied using Dipyridamole infusion with dopamine, and showed improving effect of PCI on the S and SR indices [27]. In another study performed by Thambyrajah and colleagues, 16 patients underwent exercise echocardiography before and after PCI and substantial increase in $S$ and $S R$ values were reported after successful PCI [28].

According to this study and given the potential of $S$ and SR echocardiography method in examining heart movements, wider usage and training of S/SR imaging is recommended, and S/SR imaging studies should be performed in intermittent intervals to follow the treatment response.

\section{Study Limitations}

Our study had a few limitations: The most important limitation was that S/SR technique is angle-dependent and deformation can only be assessed longitudinally. We attempted to overcome this problem by reaching high frame rates by narrowing the image window and centralizing the assessed image.

The image quality and artifacts were another limitation, which led to exclusion of some patients from the study during the follow-up period, and new patients were recruited instead. Third, the collaterals that were formed in patients during acute ischemia were not included in the evaluation; however, there is insufficient data concerning this issue in the literature. The fourth limitation was that patient group used several other drugs (beta- blockers and angiotensin converting enzyme inhibitors and some others) affecting hemodynamics and myocardial functions from the beginning of the study. Fifth, in this study, prior MI was an exclusion criterion, and the methods described cannot be applied to patients with pre-existing systolic dysfunction. As all patients had a sinus rhythm, no conclusion can be drawn in patients with atrial fibrillation or other arrhythmias. Although no confounding was demonstrated in our material, differences in loading conditions and inotropy may influence parameters of left ventricular systolic function. Therefore, results should be interpreted with care when these factors may be altered.

\section{CONCLUSIONS}

The therapeutic effect of PCI on the deformation values was observed in the first week. Due to limitations of current echocardiography indices in assessing appropriate and successful PCI responses, using $S$ and SR indices (particularly SR) seems to be an appropriate solution to achieve this goal. Evaluation of recovery in the shortest time can be pointed as the most important advantage of this method. Also this study showed that echocardiography indices such as S and SR can be used as reliable predictors for ischemia and cardiac dysfunction in accordance with some previous studies. Regarding this issue S and SR imaging can be used for predicting the severity of ischemia and need for revascularization and checking the response of various ischemic areas to revascularization.

\section{Conflict of Interest}

Authors declare that they have no conflict of interest.

\section{REFERENCES}

1. Zipes DP, Libby P, Bonow RO, Mann DL, Tomaselli GF. Braunwald's heart disease: a textbook of cardiovascular medicine. 11th ed. Philadelphia: Saunders; 2019.

2. Sutherland GR, Di Salvo G, Claus P, D'Hooge J, Bijnens B. Strain and strain rate imaging: a new clinical approach to quantifying regional myocardial function. $\mathrm{J} \mathrm{Am}$ Soc Echocardiogr. 2004;17(7):788-802. doi: 10.1016/j.echo.2004 .03 .027 pmid: 15220909

3. Karvandi M. Assessment of the Left Ventricular Deformable Indices (Strain Components) in Different Echocardiography Systems. Int J Cardiovasc Pract. 2018;3(4):65-9. doi: 10.21859/ijcp-03041

4. Edvardsen T, Skulstad H, Aakhus S, Urheim S, Ihlen H. Regional myocardial systolic function during acute myocardial ischemia assessed by strain Doppler echocardiography. J Am Coll Cardiol. 2001;37(3):726-30. doi: 10.1016/S07351097(00)01160-8 pmid: 11693743

5. Pislaru C, Abraham TP, Belohlavek M. Strain and strain rate echocardiography. Curr Opin Cardiol. 2002;17(5):443-54. doi: 10.1097/00001573-200209000-00002 pmid: 12357119

6. Voigt JU, Flachskampf FA. Strain and strain rate. New and clinically relevant echo parameters of regional myocardial function. Z Kardiol. 2004;93(4):249-58. doi: 10.1007/s00392-004-0047-7 pmid: 15085369

7. Zhang Y, Chan AK, Yu CM, Yip GW, Fung JW, Lam WW, et al. Strain rate imaging differentiates transmural from nontransmural myocardial infarction: a validation study using delayed-enhancement magnetic resonance imaging. J Am Coll Cardiol. 2005;46(5):864-71. doi: 10.1016/j.jacc.2005.05.054 pmid: 16139138

8. Dagdelen S, Yuce M, Ergelen M, Pala S, Kyrma C. Quantitation of papillary muscle function with tissue and strain Doppler echocardiography measures papillary muscle contractile functions. Echocardiography. 2003;20(2):137-44. doi: 10.1046/j.1540-8175.2003.03007.x pmid: 12848678 
9. Koyama J, Ray-Sequin PA, Falk RH. Longitudinal myocardial function assessed by tissue velocity, strain, and strain rate tissue Doppler echocardiography in patients with $\mathrm{AL}$ (primary) cardiac amyloidosis. Circulation. 2003;107(19):2446-52. doi: 10.1161/01.CIR.0000068313.67758.4F pmid: 12743000

10. Kato TS, Noda A, Izawa H, Yamada A, Obata K, Nagata K, et al. Discrimination of nonobstructive hypertrophic cardiomyopathy from hypertensive left ventricular hypertrophy on the basis of strain rate imaging by tissue Doppler ultrasonography. Circulation. 2004;110(25):380814. doi: 10.1161/01.CIR.0000150334.69355.00 pmid: 15583080

11. Weidemann F, Eyskens B, Mertens L, Dommke C, Kowalski $\mathrm{M}$, Simmons L, et al. Quantification of regional right and left ventricular function by ultrasonic strain rate and strain indexes after surgical repair of tetralogy of fallot. American J Cardio. 2002;90(2):133-8. doi: 10.1016/s0002-9149(02)02435-9

12. Frigiola A, Redington AN, Cullen S, Vogel M. Pulmonary regurgitation is an important determinant of right ventricular contractile dysfunction in patients with surgically repaired tetralogy of Fallot. Circulation. 2004;110(11 Suppl 1):II153-7. doi: 10.1161/01.CIR.0000138397.60956.c2 pmid: 15364855

13. Eyskens B, Weidemann F, Kowalski M, Bogaert J, Dymarkowski S, Bijnens B, et al. Regional right and left ventricular function after the Senning operation: an ultrasonic study of strain rate and strain. Cardiol Young. 2004;14(3):25564. doi: $10.1017 /$ S1047951104003038 pmid: 15680019

14. Lee R, Hanekom L, Marwick TH, Leano R, Wahi S. Prediction of subclinical left ventricular dysfunction with strain rate imaging in patients with asymptomatic severe mitral regurgitation. Am J Cardiol. 2004;94(10):1333-7. doi: 10.1016/j.amjcard.2004.07.129 pmid: 15541262

15. Andersen NH, Poulsen SH, Eiskjaer H, Poulsen PL, Mogensen CE. Decreased left ventricular longitudinal contraction in normotensive and normoalbuminuric patients with Type II diabetes mellitus: a Doppler tissue tracking and strain rate echocardiography study. Clin Sci (Lond). 2003;105(1):59-66. doi: 10.1042/CS20020303 pmid: 12639218

16. Mottram PM, Haluska B, Leano R, Cowley D, Stowasser M, Marwick TH. Effect of aldosterone antagonism on myocardial dysfunction in hypertensive patients with diastolic heart failure. Circulation. 2004;110(5):558-65. doi: 10.1161/01.CI R.0000138680.89536.A9 pmid: 15277317

17. Voigt J-U, Daniel W. New techniques for the quantification of myocardial function: acoustic quantification, color kinesis, tissue Doppler and" strain rate imaging". Zeitschrift fur Kardiologie. 2000;89:97-103.

18. Weidemann F, Breunig F, Beer M, Sandstede J, Turschner O, Voelker W, et al. Improvement of cardiac function during enzyme replacement therapy in patients with Fabry disease: a prospective strain rate imaging study. Circulation. 2003;108(11):1299-301. doi: 10.1161/01.CIR.0000091253. 71282.04 pmid: 12952834
19. Voigt J-U, Daniel W. New techniques for the quantification of myocardial function: acoustic quantification, color kinesis, tissue Doppler and" strain rate imaging". Zeitschrift fur Kardiologie. 2000;89(4):97-103.

20. Heimdal A, Stoylen A, Torp H, Skjaerpe T. Real-time strain rate imaging of the left ventricle by ultrasound. J Am Soc Echocardiogr. 1998;11(11):1013-9. doi: 10.1016/S08947317(98)70151-8 pmid: 9812093

21. Marwick TH. Measurement of strain and strain rate by echocardiography: ready for prime time? J Am Coll Cardiol. 2006;47(7):1313-27. doi: 10.1016/j.jacc.2005.11.063 pmid: 16580516

22. Armstrong G, Pasquet A, Fukamachi K, Cardon L, Olstad B, Marwick T. Use of peak systolic strain as an index of regional left ventricular function: comparison with tissue Doppler velocity during dobutamine stress and myocardial ischemia. J Am Soc Echocardiogr. 2000;13(8):731-7. doi: 10.1067/mj e.2000.105912 pmid: 10936816

23. Aksakal E, Gurlertop Y, Seven B, Sevimli S, Gundogdu F, Arslan S, et al. Assessment of the regional myocardial deformation changes and viability in anterior acute myocardial infarction patients by strain and strain rate imaging. Anadolu Kardiyoloji Dergisi/The Anatolian Journal of Cardiology. 2010;10(6):479-87. doi: 10.5152/akd.2010.166

24. Kukulski T, Jamal F, D'Hooge J, Bijnens B, De Scheerder I, Sutherland GR. Acute changes in systolic and diastolic events during clinical coronary angioplasty: a comparison of regional velocity, strain rate, and strain measurement. J Am Soc Echocardiogr. 2002;15(1):1-12. doi: 10.1067/mje.2002.1148 44 pmid: 11781548

25. Tanaka H, Kawai H, Tatsumi K, Kataoka T, Onishi T, Nose T, et al. Improved regional myocardial diastolic function assessed by strain rate imaging in patients with coronary artery disease undergoing percutaneous coronary intervention. J Am Soc Echocardiogr. 2006;19(6):756-62. doi: 10.1016/j.echo.200 6.01.008 pmid: 16762753

26. Liang HY, Cauduro S, Pellikka P, Wang J, Urheim S, Yang EH, et al. Usefulness of two-dimensional speckle strain for evaluation of left ventricular diastolic deformation in patients with coronary artery disease. Am J Cardiol. 2006;98(12):15816. doi: 10.1016/j.amjcard.2006.07.038 pmid: 17145214

27. Haghighi ZO, Moghadam RH, Ahmad A, Moladoost $\mathrm{H}$, Khajavi A. Left ventricular strain rate is capable in predicting severity of coronary artery stenosis, Heart failure and transplantation Rajaei Cardiovascular, Medical \& Research Center. Arch Iran Med. 2007;10(2):387-9.

28. Thambyrajah J, Vijayalakshmi K, Graham RJ, Turley AJ, de Belder MA, Stewart MJ. Strain rate imaging pre- and postpercutaneous coronary intervention: a potential role in the objective detection of ischaemia in exercise stress echocardiography. Eur J Echocardiogr. 2008;9(5):646-54. doi: 10.1093/ejechocard/jen035 pmid: 18296398 